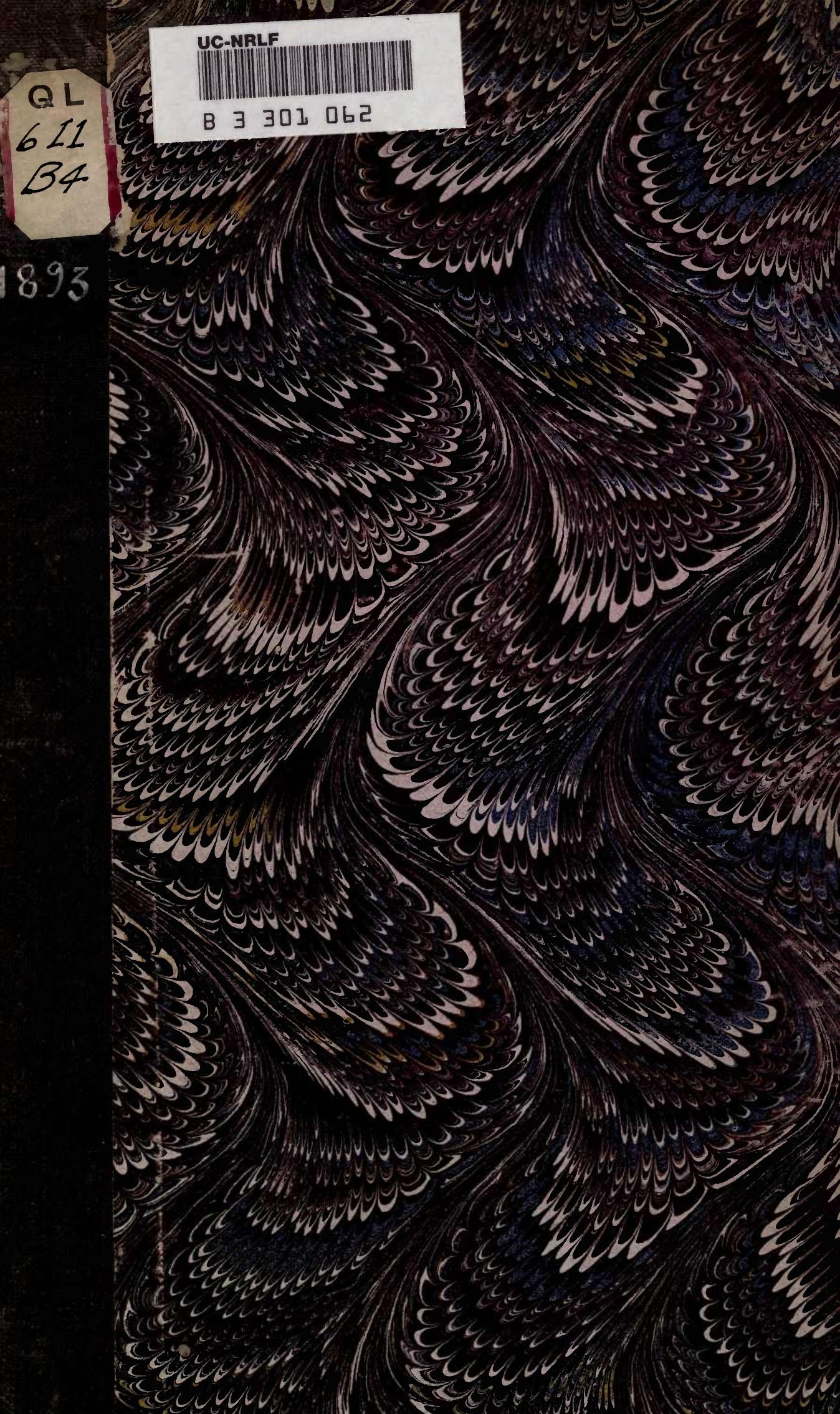

893

3 (c) (2) s. 1. 250

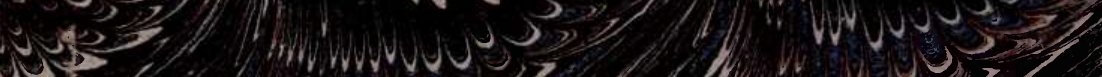

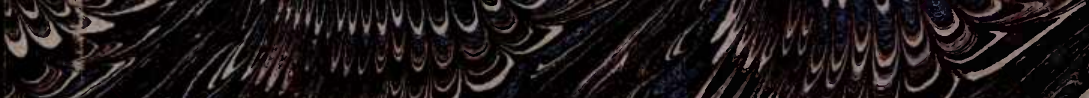

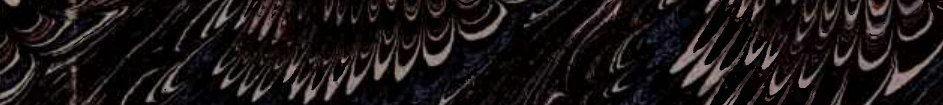



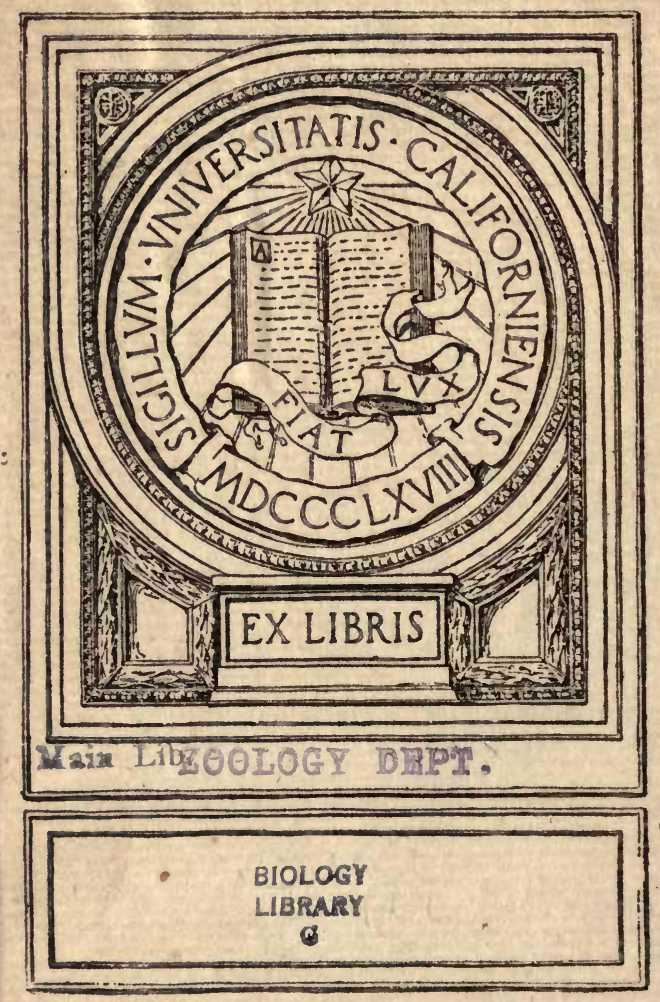



$$
\text { wia sn. Zodogm Dept. }
$$




\section{The Structure of the Pharyngeal Bars of Amphioxus.}

By

W. Blaxland Benhau, D.Sc.Lond., Hon. M.A.Oxon.,

Aldrichian Demonstrator of Comparative Anatomy in the University of Oxford.

With $\overline{\text { Plates } 6}$ and 7.

IT may be thought that the structure of the pharyngeal bars of Amphioxus is sufficiently known, after the description by Lankester, and more recently by Spengel; but there still remains a certain amount of doubt as to some points in the structure of the tongue or secondary bar, although recent authors are in agreement as to the general structure of the primary bar. It is to the tongue har, therefore, that I have more particularly directed my attention.

Spengel contradicted Professor Lankester on several points, both with regard to matters of observation, and more especially with regard to certain interpretations, in a very dogmatic and, indeed, discourteous manner. I was surprised to find that Professor Spengel himself is by no means correct in sundry matters of mere observation.

It will be remembered that Lankester, in addition to his account of the structure of the gill bars-which was, like his figures, in great advance of the work of previous writers on the subject-made certain statements with regard to the spaces within these bars; he attempted to distinguish, not only in the 


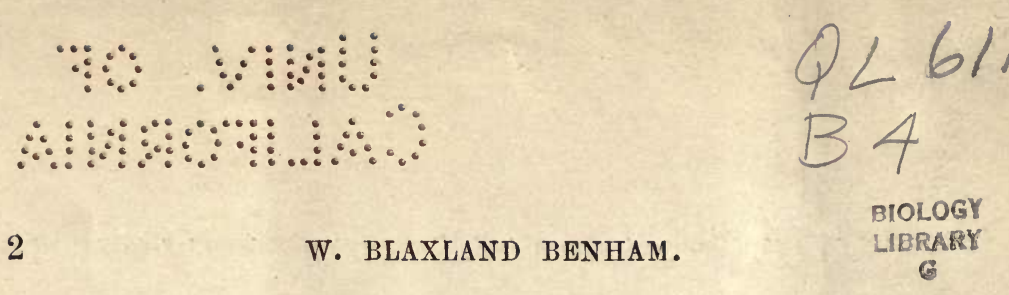

bars, but in Amphioxus as a whole, cœlomic spaces from blood-vessels. It is chiefly with regard to the interpretation of the spaces within the tongue bars that Spengel joins issue with him, and it was to this part of the subject that I directed my attention last summer in the endeavour more especially to decide whether the cavity traversing the "chitinoid" rod of the tongue bar be cœlom (Lankester) or blood-vessel (Spengel).

I hoped to decide the question by the examination of specimens which had been fed with carmine; and for this purpose Professor Lankester requested Mr. A. Willey, who was then at Naples, to feed some animals and preserve them for me. My thanks are due to Mr. Willey for so doing. Unfortunately, however, these carmine-fed specimens have not been of much value for my purpose, and I was compelled to fall back upon carefully preserved specimens (in picro-sulphuric acid) stained in various media. This was the method followed both by Lankester and by Spengel-careful tracing of spaces from section to section in order to ascertain their communication with other cavities about whose nature there is no doubt.

Before I had completed my work, Boveri's most interesting paper on the nephridia was published. Boveri found, as I had, that Spengel, both in incomplete observation and in certain interpretations, had fallen into errors similar to those which with an accompaniment of gratuitous insolence he had attributed to Lankester.

This short note may conveniently be divided as follows:

A. Description of the tongue bar, according to my own observations, and comparison of it with the primary bar.

B. Interpretations of the parts of the tongue bar.

c. The observations of recent observers.

D. Certain abnormalities in the pharyngeal bars.

The authors who have described and figured the gill bars of A mphioxus, to whom I shall have occasion to refer, are-

1. Stieda.-"Studien üb. d. Amphioxus lanceolatus," "Mém. Ac. Sci. Pétersbourg,' xix, 1873. 
2. Langerhans.- "Zur Anat. d. Amphioxus lanceolatus," "Arch. f. mikr. Anat.'’ xii, 1876.

3. Schnelder. - 'Beiträge zur Vergleich. Anat. und Entwickel. der Wirbelthiere,' 1879.

4. Iankfster.- "Contributions to the Knowledge of A mphioxus lanceo. latus," 'Quart. Journ. Micr. Sci.,' xxix.

5. Spengez.- "Beit. z. Kenntniss d. Kiemen des Amphiox us," "Zool. Jahrbuch' (Anat.), iv, 1891.

6. BoverI._ "Die Nierencanalchen des Amphioxus," "Zool. Jahrbuch" (Anat.), v, 1892.

In addition to these, a bibliography relating to $\mathrm{A} \mathrm{m} p h i o x$ us will be found in Lankester's paper.

\section{A. The Tongue Bar.}

The tongue (or secondary) bar is usually distinguished from the primary bar $(a)$ in being supported by a tubular skeletal rod in place of the double rod of the primary bar, $(b)$ and in being without any cœlom between the rod and the atrial epithelium. It is unnecessary to describe the relations of the bars to one another or to neighbouring parts of the animal, as these matters have been fully described and illustrated by recent writers on the subject.

The structure of the bar is most readily seen in its transverse sections, but such sections-accurately transverse to the bar -are not so easily obtained; in sections transverse to the long axis of Amphioxus, only one or two bars on each side of the pharynx will be cut transversely, though in the pre-hepatic region more bars are so cut, and still more are very nearly transversely cut, than is the case posteriorly. But by varying the obliquity of the plane of section to that of the long axis of the body, I was able, ultimately, to obtain sections which cut nearly the whole series of bars in any section almost accurately at right angles to their length.

It appears to me that this is most important, for the discrepancies in various descriptions and figures of the bar are doubtless due to the more or less obliquity of the sections.

Another matter which must be taken into serious account is the mode of preparation and the character of the stain; for I 
have noted in my series-treated differently in both these respects-various differences due to shrinkage and such effects, which suggest the cause of certain omissions by some authors, and of wrong interpretations and other errors.

I have found that Kleinenberg's fluid (picro-sulphuric acid) is the preservative which produces less distortion than other reagents. Cochineal stains, especially Mayer's alcoholic cochineal, serves best for the demonstration of blood in the vessels and for the examination of the skeletal tissues.

Hæmatoxylin is, of course, useful for the nuclei, but cochineal gives better results in the case of cell-bodies.

Some of the animals were stained in bulk; in other cases the sections were stained on the slide.

I proceed now to a description of a trausverse section of a tonguc bar, as elucidated by the examination of sections treated in different ways, as well as of isolated portions of pharyngeal wall.

Such a section is a narrow bar (about three times as long as it is wide), presenting two ends and two sides: one end, the Outer end, projects into the atrium, and is covered by atrial epithelium; the opposite end, or Inner end, projects into the cavity of the pharynx, and is lined by hypoblast. The sides are directed (roughly) anteriorly and posteriorly.

The bar consists almost entirely of columnar epithelial cells, the inner ends of which abut upon a membrane, the cutis (I follow here Professor Lankester), throughout the greater part of the bar; whilst at the outer end the cells rest upon the skeletal rod, which I regard as merely a specialised part of this cutis.

The character of the epithelium, however, differs at the two ends and at the sides. At the Inner or pharyngeal end the nuclei are arranged in three groups, a central group and a lateral group on each side, as Lankester was the first to point out. The nuclei of the central group are arranged in two more or less curved rows (as in fig. 1), but this arrangement is due not to the existence of two layers of cells, but to the fact that alternately the nuclei are situated nearer to or 
further from the base of the cell. The nuclei are elongated and oval; they are placed much closer to one another than my figure represents, and as they stain deeply are very conspicuous. In thick sections it is difficult to determine whether one has to do with a single row of very elongated cells (as Lankester believed), or with several rows of them; this difficulty is emphasised when the sections are not accurately transverse. But in thin sections, successfully cut, it is easily seen that the nuclei are arranged as I describe them.

The cells to which these nuclei belong are, therefore, as long as the epithelium is thick; they are very narrow peripherally and swollen at the nuclear level, producing the flaskshaped appearance of the whole group. These cells carry cilia which are considerably longer than those carried by the lateral groups of cells at this inner end; and it is curious that of previous observers, only Spengel and Boveri have noted this special bundle of cilia. The free ends of the cells are provided with a very fincly striated border, which comes out well in cochineal preparations, but which is not differentiated by other stains used.

Each lateral group of nuclei consists of a single row curving downwards from the central group towards each side, somewhat in the way represented by Lankester; but I find that these nuclei, which are long and narrow, are not arranged quite in the fan-shaped manner represented by him.

The cells containing these nuclei carry quite short ciliaentirely overlooked by Spengel and Boveri,-and their free ends are not provided with a striated border. The shape of this inner end has been very variously represented, as the copies of previous figures on Pl. 6 will show.

The side of the bar presents some four or five rows of small nuclei forming a broad band, about two thirds the whole width of the epithelium. These nuclei are not circular, as most observers have represented them (owing to the obliquity of the section, as I know from experience), but are oval, with the long axis directed vertically to the plane of the surface. Langerhans appears to have noted their oval shape. 
Here, again, these rows of nuclei do not represent as many layers of cells, for there is but a single layer of very long and very narrow cells, with the nuclei at different levels in neighbouring cells. In some of my preparations these cells are more or less macerated, so that I was able to confirm the description of them given by Langerhans (see fig. 19). Each cell, or at any rate most cells-for it is impossible to be absolutely certain that all the cells reach the surface, though $I$ believe this to be the case-carries a single very long cilium, and presents a finely striated border. The nuclei of the lowermost row appear to be slightly longer than those of other rows, and are close to the septal membrane or cutis, along which they form a very well-marked series. Towards the extremity of the side, both outwards and inwards, i. e. towards the atrial end and the pharyngeal end, the lowest row of nuclei curve upwards towards the surface, so that the epithelial cells become shorter and shorter, and the number of rows less and less, till finally there is but a single nucleus contained in a cell not much longer than itself (see fig. 1). At the inner end of the bar the thin membrane-like cutis curves outwards towards the surface, and naturally the row of nuclei take on this curvature. At the opposite end of the bar the row of nuclei follow the curve of the chitinoid rod; but at this end, for a short space, the epithelium is overlapped, as it were, by a row of three or four cubical cells containing pigment, and not carrying cilia. These cells are part of the atrial epithelium, the invaginated epiblast of the pharyngeal slits. These pigmented cells differ from those hitherto mentioned in containing circular (spherical) nuclei, and herein agree with the cells constituting the epithelium of the Outer end of the bar.

This atrial epithelium is characterised by the larger size of its cells, the absence of cilia, and the presence of relatively small round nuclei, which are placed at different levels in the cells (fig. 1). These cells are highest in the middle of this end -i. e. at the end of the long axis of the section through the bar -and decrease in length at each side of this point till they graduate into the cubical pigmented cells which overlap the 
cells of the sides of the bar. In the tongue bar these cells are all of one kind (fig. 18), whereas in the primary bar two kinds of cell (fig. 17, $a, b$ ) are present, one $(a)$ being vacuolated, the other $(b)$ more granular. Langerhans noted this fact, though he exaggerated the difference. So much for the epithelium of the bar. I shall point out later how far these statements of fact differ from those of my predecessors. ${ }^{1}$

Turning now to the cutis of the bar, i.e. the septal membrane and the chitinoid rod: the septal membrane forms a very thin sheet of tissue traversing the greater part of the long axis of the section, and separating the epithelium of the two sides. At the base of the epithelium of the Inner or pharyngeal end of the bar the septal membrane splits into two, and each of the two branches curves outwards to-, wards the surface; this forking of the membrane leaves a $\mathrm{V}$-shaped space, which is converted into a triangle by a membrane (cutis) at the base of the pharyngeal epithelium.

In this triangular space is a blood-vessel, as Spengel and Boveri have already described (figs. 7, 8). It may be called the internal or Visceral vessel. At the opposite end the septal membrane similarly divides into two, each half of which appears to be continuous with the corresponding side of the rod (fig. 1). This space, which differs somewhat in shape according to the shape of the rod, but which is, on the whole, triangular, also contains a blood-vessel-the external, or somatic vessel. This vessel was observed by Lankester (fig. 6), but overlooked by Spengel (fig. 7), although he represents the space here, whilst Boveri described it as existing only in the primary bar. From the fact that, at each extremity, this septal membrane forks, and from theoretical considerations, I believed this membrane to be in reality double, as indeed it is represented by Stieda's figure (Pl. 6, fig. 3). But I was for a long time unable to assure myself of this fact. I was unable to satisfy myself as to the presence of two membranes here, for, owing to the refrangibility of the structure, it is difficult to make certain whether

I I have not observed the "muscle-cells" in the har described by Rohon and by Langerhans, J. Müller and Schmeider. 
one sees a double outline to the single membrane (such as Boveri represents, Pl. 6, fig. 8) or two closely apposed membranes.

Spengel vehemently animadverts on Lankester's interpretation of this membrane as a mesoblastic cutis, and insists on its being a "basement membrane," i.e. epiblastic. Lankester was, it seems to me, in error in referring the origin of this membrane to the deepest layer of nuclei in the sides of the bar; at the same time, if we consider the relations of this membrane to the rod and to the vessels at each end, we cannot doubt that the rod and the membrane have the same origin. The rod would scarcely, I presume, be referred by Spengel to the epiblast. I believe, however, that I have decided that the rod is mesoblastic by the discovery of the flattened nuclei pressed against its inner surface ( $\mathrm{Pl} .7$, fig. 13); and we may conclude that the rods in both bars are produced by the flattened epithelium which, as Hatschek has pointed out, forms the "connective tissue" throughout the body of Amphioxus. If the rod is mesoblastic, then a priori we may believe the eptal membrane, which is absolutely continuous with it, to be also mesoblastic; but further, I have detected flattened $n$ uclei in this axis of the bar, i. e. between the two halves of the closely apposed membranes. I searched long and carefully for any nuclei in relation to the septal membrane, and ultimately, in my series of accurately transverse sections, I was able, with the aid of Zeiss's apochromatic, to observe some structures which I believed to be nuclei. However, I was not absolutely certain of their existence, owing to the refrangibility of the membrane and the denseness with which the epithelial nuclei are packed; but in a series of sections intended to be horizontal, and stained in hæmatoxylin, some of the bars were cut longitudinally for a considerable distance-some six or seven times the length of an ordinary transverse section of a bar, -and here I saw distinctly elongated and much compressed nuclei (fig. 21) of fair size, lying between the two membranes. 'These, like the nuclei surrounding cœlomic spaces, are not rich in chromatin, and do not take the stain easily. We may, 
therefore, conclude-as, from a priori reasoning, we should be led to believe-that this septal membrane is double, and is mesoblastic, and not a basement membrane.

The chitinoid rod of the tongue bar is distinguished, as is well known, from that in the primary bar by the presence of a canal-it is a perforated rod.

The shape of the section of the rod varies considerably, both in different bars and even in different parts of the same bar, but that represented in this figure may be regarded as the most general shape. Not only the general outline, but the shape and extent of the contained space are included in the above statement as to the variability of the rod. Professor Lankester has already figured several such variations (loc. cit., pl. xxxvi, B), and others will be found on the plate illustrating this note ( $\mathrm{Pl}$. 7, figs. 13-16). But most generally the rod presents a somewhat triangular section, with rounded angle at the base, and a notch-more or less prefound-at the apex. This notch forms a part of the internal triangular cavity partially bounded by the septal membrane and occupied by the somatic blood-vessel.

The chief cavity - the canal-of the rod is similarly more or less triangular in section, rarely round, as Lankester represents it, though this shape does occur. The thickness of the outer wall presents very interesting variations: more usually it is nearly as thick as the sides, but it may be very much thinner (as in fig. 14); it may be represented merely by a thin membrane little thicker than the septal membrane, and much thinner than the cutis (basement membrane-Spengel) below the atrial epithelium of the primary bar. Further, this rod may be represented by a couple of curved pieces, which do not quite meet externally, so that the curtained cavity is without an outer wall (fig. 15). This is always the case at the points where a synapticulum joins the tongue bar (fig. 31 ), but it also occasionally occurs elsewhere.

This cavity frequently appears quite empty, invariably so in my hæmatoxylin preparations; but in sections stained with cochineal, granular matter is very frequently present in greater 
or less abundance $;^{1}$ and $I$ have sometimes noticed an apparent division of this cavity by a transverse partition, the granulations having a slightly different appearance in the two sides of this partition (fig. 14). Moreover in this same series of sections, as also in sections stained with Weigert's picrocarmine, the blood in undoubted blood-vessels, such as hepatic vessels, dorsal and subendostylar vessels, takes on a characteristic deep red colour-deeper than the tint taken by the skeletal tissues, - so that I am able most definitely to state that there are three blood-vessels traversing the tongue bar, not two, only as Spengel and Boveri believed (c.f. fig. I with figs. 7, 8).

Of these three vessels, two occur always at opposite extremities of the septal membrane, in the triangular spaces already mentioned; the third lies inside the rod, and may be called the skeletal vessel. Usually it has the position represented in fig. 1-in the chief canal of the rod, but it does not appear to fill this canal; I can generally detect a slight space around it. This may, of course, be due to shrinkage of the clotted blood; but the apparent existence in some cases of a partition (see fig. 14 and the explanation of it) favours my view, as also does the condition of things represented in fig. 13, where the vessel is passing out of the cavity, that this cavity of the rod is colom, which contains a blood-vessel. This view is further strengthened by the fact that, both in my hæmatoxylin preparations (where the blood-vessels are not evident) and in my cochineal sections, $I$ have detected flattened nuclei pressed against the inner surface of the rod, as represented diagrammatically in fig. 1, and accurately drawn from the object in fig. 13. This, I may say, has not been an occasional occurrence, but can be seen in many accurately transverse sections of the bar.

In some of the variations from the normal the rod presents a small cavity about midway between the main canal and the apical notch (figs. 13, 14), and this cavity is usually connected

1 Spengel mentions the presence of finely granular material in the canal of the hollow rod (loc. cit., p. 278). 
with the former by a narrow channel; in this accessory cavity I have sometimes seen a vessel in addition to that in the chief canal, and sometimes I have not detected the latter. I take it that there may be occasional anastomosis between the "somatic" vessel in the notch and the skeletal vessel in the canal.

\section{Comparison of the Tongue Bar and Primary Bar.}

I wish now to compare such a transverse section of a tongue bar with that of a primary bar, so far as regards the Outer end. Compare my figures 1 and 2 and that copied from Boveri (fig. 12). In the primary bar Boveri describes, as I myself find, three vessels - $(a)$ the inner, or visceral, and $(b)$ outer, or somatic, as is the case in the tongue bar, and $(c)$ the third or skeletaI (first observed by Spengel) outside the cœlom of the primary bar, between the atrial epiblast and the "cutis" (bascment inembrane of Spengel). This last vessel may project through the cutis into the colom, and at the base of the bar, where it springs from the endostyle, and where the rod forks, this blood-vessel lies in the angle of the fork, i. e. in the cœlom itself (fig. 30, $a$ ), as Spengel has figured. In the tongue bar the first two of these vessels are identical with those of the primary, and one can scarcely resist the idea that the third, or skeletal vessel inside the rod, may correspond with the subepidermal vessel of the primary bar; it differs from it, however, in one very important point, namely, in the absence of any connection with the subendostylar vessel. But now turn to the rod itsclf. This is, in the primary bar, made up of two pieces, more or less fused according to the region of the bar (see fig. 30, $a, b, c$ ), so as to form a triangle, usually with a more or less pronounced notch, or linear channel, arising from near the base (see fig. 9); or again, as Schneider figured and as I have frequently observed, a triradiate split in its centre ${ }^{l}$ (fig. 30, c). Outside the rod comes the cœlom-every one is agreed about that-lined by flattened cells; and outside them the cutis,

1 'This usually is due to the softer nature of the central part of this rod, and is not really a cavity: the rod presents irregularly concentric markings, as if shrunk, and is firmer externally. 
which varies considerably in thickness, and can be traced, as Boveri's figure shows, into the rod at each extremity (Pl. 6, fig. 12). This cutis stains exactly like the rod in cochineal, and also like the rod is unstained in hæmatoxylin. Sometimes the cleft in the rod is more pronounced, and gives rise to a more definite channel (see Lankester, xxxvi B, fig. $3, f$ ) open to the cœlom. Such a condition of things is represented in my $\mathrm{Pl}$. 7, fig. 31, which passes through a primary rod (P. 1) at the level of a synapticulum, ${ }^{1}$ and should be compared with certain variations in the rod of the tongue bar in the same figure and in fig. 15, and one is struck with the resemblance between the two.

I would suggest that the distinction between the two rods, viz. that of the primary bar and that of the tongue bar, is not so profound as one would be led to think from the use of the terms solid (or bifid) rod and hollow rod. We have seen that not infrequently the rod of the tongue bar is formed of two pieces (fig. 15), whilst, on the other hand, the rod of the primary bar may enclose a cavity. But I think the real distinction between them is that in the tongue rod the subepithelial portion is usually and typically as thick as the sides, and distinctly continuous therewith; whereas in the primary rod the extra-colomic piece (subepithelial) is thinner, and, owing to the greater development of the cœlom here, is more widely separated from the rest of the rod. This suggestion occurred to me forcibly in examining the connections of the synapticula with the two bars.

In a lucky series of sections, cutting the bars very accurately transversely, one often gets the whole synapticulum in sections, passing from one primary bar to the next, and showing the connection of the rod in the transverse bar with those of the main bars (fig. 31). Starting with the tongue bar $(T$.$) , the rod forks, so that its contained cavity is no longer$ bounded by a chitinoid wall; one branch of the fork passes towards each of the adjacent primary bars, and is continuous, not with the main part of the rod itself, but with

1 Spengel gives a figure very similar to this one in pl. xvii, fig. 13, illustrating his paper. 
the cutis (basement membrane of Spengel), or extra-cœlomic portion of the rod, as I would regard it. But this apparent forking of the tongue rod is due merely to the passage of the contained blood-vessel out of the rod to the vessels of the adjacent primary bars; so that in reality, as many sections show, the rod of the connecting bar, i. e. the synapticulum, is connected on the one hand with the extra-cœlomic portion of the tongue rod, and on the other with the extra-colomic "cutis" of the primary bar.

A second difference between the rods is that the skeletal vessel is inside the colom in the tongue bar, but outside it in the primary bar over the greater part of its extent, though, in the lower part of the latter bar, it is intra-cœlomic, as in the tongue bar (fig. $30, a$ ). I have sometimes seen a small cavity outside the rod in the tongue bar, but $I$ have not been able to satisfy myself as to its nature; it may be merely artifact.

3. Summary of my Observations and Interpretations.

1. The epithelium of the bar is everywhere only one cell in thickness.

2. The arrangement of the cells at the pharyngeal end of the bar, both in the primary and in the tongue, is much more definite than previous observers, except Lankester, have figured and described; the central group, contrary to Lankester's opinion, presents two rows of nuclei, and carries a bundle of very long cilia; the lateral groups carry quite short cilia.'

3. The nuclei at the sides of the bar are oval and not round, and the lowest row has nothing to do with the septal membrane.

4. There are three blood-vessels in the tongue, as in the

1 This differentiation of the cilia round the bar may be compared with that occurring in the gill filanents of Lamellibranchs, and in the cirri of Brachiopods, where there are similarly bundles of long cilia, situated at the sides or angles, and shorter cilia elsewhere. The existence of a skeletal tissue in these cases is a further analogous resemblance. 
primary, bar; (a) the visceral vessel at the pharyngeal end of the bar; (b) the somatic vessel in the apical notch of the rod; and $(c)$ the skeletal vessel inside the rod: the last two anastomose here and there.

5. The cavity of the rod is colom, is lined by flat cells, and contains this skeletal blood-vessel.

6. The outer wall of this cœlom is homologous with the extra-cœlomic cutis (Spengel's basement membrane) of the primary bar.

7. The septal membrane and the rod are mesoblastic, and the nuclei of the cells forming them are here recorded for the first time.

c. The Observations of Recent Observers.

I will now pass on to a brief survey of the various descriptions and figures of the tongue bar of previous writers, copies of whose figures are represented on Pl. 6, and in the explanation of these, the references whence the figures are taken. Stieda, Langerhans, and Schneider saw no modifications of the epithelium at the pharyngeal end of the bar. Lankester was the first to observe this, and his figures represent more accurately than do those of his successors, Spengel and Boveri, the actual arrangement. As I have already pointed out, however, he missed the fact that the middle group presents two rows of nuclei. This is equally overlooked by Boveri, while Spengel's drawing is not quite clear on this point, and neither of these latter indicate the much greater length of the nuclei in this part of the bar. So far as the general shape of the pharyngeal end of the bar is concerned, Spengel's and Boveri's drawings show it fairly. Fig. 12 from Boveri is taken from quite the upper end of the bar, hence the peculiar shape of this end. Lankester is alone in regarding-as I believe wrongly - the epithelium of the sides of the bar as in several layers. Spengel points this out; but he, like all my predecessors, with the doubtful exception of Schneider and Isangerhans, represents small round instead of oval nuclei here.

The authors, as will be seen from the reproductions of 
their figures, represent the characters of the atrial epithelium at the upper end of the bar correctly, with the exception of Langerhans, who describes each cell here as bearing a flagellum.

Stieda and Langerhans did not recognise the differences in the length of the cilia round the bar. Schneider is the first to figure the long cilia at the sides, and the remaining authors follow him. Spengel is the first to note this tuft of long cilia at the pharyngeal end; but both he and Boveri ${ }^{1}$ overlooked the short cilia carried by the lateral groups of cells at this end.

With regard to the contained vessels in the primary bar, Langerhans entirely missed the vessel at each end of the septal membrane. Schneider and Lankester saw only one vessel-that at the outer end of the bar at the apex of the rod - the somatic vessel. Spengel most unaccountably missed this vessel, although he states that he looked carefully for one here, and his figure of the tongue bar (Pl. 6, fig. 7) shows a very narrow cleft in its position, whilst he describes the inner or visceral vessel $(v n$.$) , which is usually less noticeable than the$ other. In this respect his figure shows no advance upon that of Stieda, who also saw, but did not describe, the space at the inner end of the bar.

Boveri, however, observed this vessel (and figures it) in the primary bar (fig. 12, ve. 1), in the position already given to it by Lankester, but overlooked it in the tongue bar (fig. 8). As a matter of fact, as I have stated above, there are three vessels in each bar. Schneider and Lankester found one, the "outer or somatic" vessel; Spengel found one, the "inner or visceral vessel," but denied the somatic vessel. Boveri found both these in the primary bar, but overlooked the "outer vessel" in the tongue bar.

As to the nature of the rod cavity, Stieda and Langerhans leave it aside. ${ }^{2}$ Schneider represents (at $A$, fig. 5) "a blood-

1 It should be borne in mind, however, that Boveri did not pretend to describe the bars except in so far as they are related to the nephridia.

2 Stieda regards the granular substance in the centre of the rod (fig. 2, a) as an axial part of the rod itself. 
vessel communicating with the branchial artery." Lankester, from its relation to the subendostylar cœlom, regarded this canal in the rod as "cœlom;" whereas Spengel and Boveri look upon it as a blood-vessel, and deny its colomic character. Lankester gives half a dozen figures (loc. cit., pl. xxxvi B, figs. 5 -9) of as many consecutive sections representing the canal communicating with the subendostylar cœlom. Spengel denies this altogether, and states that the rod becomes solid before it reaches the endostyle, and there becomes continuous with the subendostylar skeleton. He further denies any communication of this rod cavity with the dorso-pharyngeal cœlom.

Now the tracing of these cavities is an extremely difficult matter, owing to the difficulty of making sections in the right plane, and I searched through section after section before I could satisfy myself as to the mode of termination of these rods. Time after time it seemed to me that Spengel was right, so far as the non-communication of the rod cavity was concerned; but in certain lucky sections I found that the plane was convenient for this purpose, and I represent five consecutive sections which show, as I believe, the continuation of the subendostylar cœlom into the cavity of the rod (Pl. 7, figs. 22-26). The series shows most certainly no continuity between the rod and the subendostylar skeleton on which Spengel insists.

I was not successful in tracing the rod cavity into the dorsopharyngeal coelom; but I attribute this to the difficulty of observation, and am by no means inclined to conclude that such a connection does not exist.

The "skeletal vessel" ceases some little way before the rod does, being connected with the vessels in the neighbouring primary bars at the lowest synapticulum.

If the hinder gill-slits be examined in a preparation of the pharynx, flattened out on a slide, and the mode of development of the "tongue" observed, it will be seen that the rod in the tongue is double at its upper end; the two pieces diverge and constitute the arcade connecting the series of rods. The tongue bar, as is knowu, is a dowugrowth from the upper 
boundary of a primary slit; the cœlom is here in the form of a canal giving off shoots to each bar, and fro them appearance presented in such a preparation, it is not an inconsistent interpretation to regard the cœlom as sharing in the downgrowth of its ventral wall. The appearance presented by the rod in the hinder gill-slits is thus : $M$.

\section{Certain Abnormal Bars.}

In one series of sections the pharynx presented a few bars containing sometimes three and sometimes two rods. In all cases these abnormal bars are "primary" bars, i. e. the rods contained within them are cleft rods, similar to those found in normal primary bars; and on each side of such abnormal bars there lies a normal tongue bar, separated by a pharyngeal slit from the abnormal one. On Plate 7, fig. 27, I represent one such bar cut at about the middle of its length, containing three rods, which are in all respects similar to one another. The bar itself is otherwise normal, and presents the usual characters of the epithelium in its various parts. Naturally the bar is much wider than an ordinary one, especially at its atrial end. The septal membrane (s.m.) is very short, but the two usual blood-vessels (vix.v. and som.v.) are present. There is not a vessel at the apex of each rod, as one might expect; the cœlom is very extensive, and dips in between the rods as the nuclei show. The usual subepidermic blood-vessel (skel.v.) is also present. But this bar, if traced upwards towards the epibranchial groove and downwards towards the endostyle, presents variations of this condition in different regions.

At its origin dorsally the three rods are fused together, but this occurs for only a very short space, and we soon tind three rods. Towards its lower end two of these (Nos. 1 and 3 ) are fused, so that the bar has but two rods; and still further a junction between these two is effected (fig. 28), and there appear to be but one rod, rather larger than usual, but evidently consisting of two united rods. Soon, however, these separate again, and $I$ take this union as representing a synapticulum.

But now the relative position of the two rods changes; 
hitherto they have been side by side, or rather anterior and posterior ; but now (fig. 29) one (No. 2) lies outside the other (Nos. 1 and 3), which occupies the normal position. I was unable to track the rods quite to their junction with the floor of the pharynx owing to the imperfection of some of the sections in this series.

Most of the other abnormal bars contained two rods, but I did not trace them all out from top to bottom, so that I am unable to state whether they always contain, at some part of their length, three rods. But I am inclined to answer this in the negative; so frequently are there only two rods that I think this is the more "usual" abnormality. There is another triple-rod bar on the opposite side of the pharynx, at about the same level as the one described, and usually, as far as I could observe, the abnormal bars are opposite.

A bar with a double rod might conceivably be.produced by closure of a primary slit between two primary bars; but there is no evidence of any formation of a slit and subsequent closure and fusion of the bounding bars. One would expect if this had happened that the colom and subepidermic vessel would be doubled, and that the pharyngeal end of the bar would exhibit some peculiarity; this I did not find to be the case. A triple-rod bar might be explained by an extension of this suggestion, namely, that two slits had remained imperforate, whilst the rods had been formed nevertheless.

\section{EXPLANATION OF PLATES 6 and 7 ,}

Illustrating Dr. W. Blaxland Benham's paper on "The Structure of the Pharyngeal Bars of Amphioxus."

In most of the figures the blood-vessels are represented black, but in fig. 14 I have drawn the actual appearance presented by the sections.

FIGS. 1 and 2.-Transverse sections of a tongue an $\mathrm{l}$ a primary bar, so far diagrammatic in that each figure is a combination of several drawings of 
different sections, which have been treated in different ways. The two figures are drawn to scale, and therefore represent the true relative sizes of the bars.

Fig. 1. A transverse section of a tongue bar of the pharynx of Amphioxus (Branchiostoma lubricum, Costa). It represents, accurately as $I$ believe, a typical section of the bar. Most of the parts are fully named on the plate. The rod contains a cavity-the colom, lined by an epithelium, whose nuclei are shown (see also Fig. 13). Within this cœlom lies a blood-vessel-the skeletal vessel. Two other blood-vessels are present in the bar, the "visceral" (Visc. Bl. vessel) and the "somatic" blood-vessel; these lie at either end of the septal membrane, between the two layers of which are shown three nuclei (see also Figs. 20, 21). The atrial epithelium consists of only one kind of cell. The grouping of the epithelial nuclei at the pharyngeal end of the bar may be noted.

Fig. 2. A transverse section of a primary bar (see explanation of Fig. 1). Here the cœlom is more extensive, and the "cutis"-or outer wall of the cœlom-is thinner than in the tongue bar. The rod itself is made up of two pieces, meeting along the middle line of the bar, and a third piece wedged between. The skeletal blood-vessel is outside the cœlom, but is in reality surrounded by the rod, i. e. "cutis." The atrial epithelium consists of two kinds of cells (see Fig. 17), viz. $a$, the vacuolated, and $b$, the granular cells.

Figs. 3 to 12 are tracings of figures published by previous observers; the only alterations that have been made are (1) colouring the rod yellow, and (2) filling in with black the spaces regarded as blood-vessels by the authors.

Fig. 3. Copied from Stieda's fig. 6, pl. i. "Transverse section of a branchial plate. $a$. The rod. $b$. Deep layer of the epithelium. $c$. Superficial layer with cilia."

Fig. 4. Copied from Langerhans, fig. 24, pl. xiii. "Transverse section through a gill bar. $m$. Epithelium. $k$. Nuclei of brauchial epithelium p.e. Pigmented epithelium. $h$. The atrial epithelium. s. Hollow gill rod."

Fig. 5. Copied from Schneider's fig. 4, pl. xiv. "Transverse section of a thin (that is, tongue) gill bar. $a$. Triangular space, a bloodvessel. A. A blood-vessel in communication with the branchial artery. $k^{1}$. The rod. p.p. Peritoneal (i. e. atrial) plate."

Fig. 6. Copied from Lankester, pl. xxxvi B, fig. 2. "Transverse section of a torgue bar. al. Left inner epithelial band. ar. Right inner epithelial band. an. Median inner epithelial band. col. Columnar lateral cells, with long cilia. $n$. Superficial nuclei. $n^{1}$. Deeper nuclei. sept. Clear septal tissue. $B l$. $v$. Supposed blood-vessel, ending blindly at the ventral extremity. pig. Lateral groups of pigment in the atrial epithelium. at. ep. Atrial epithelium (epidermic)."

Fig. 7. Copied from Spengel, fig. 19, pl. xviii. "Transverse section of a tongue bar. vz. Chief vessel of the bar. vn. Accessory vessel." 
Fig. 8. Copied from Boveri's fig. 14, pl. xxxiii. "Transverse section of tongue bar at the level of the nephridium. neph. Position of nephridium. vill. Inner axial vessel. ve $e^{11}$. Outer axial vessel."

Fig. 9. Copied from Schneider, pl. xiv, fig. 3. "Transverse section of a thick (i. e. primary) gill bar. $A^{1}, A^{2}$. Blood-vessels which are in communication with the branchial artery. $a$. Triangular space, bloodvessel. $p . p$. Peritoneal (i.e. atrial) plate. $V$. Vein in communication with the subvertebral vein, and the venous space around the branchial artery. $k_{2}$. The thick rod."

Fig. 10. Copied from Lankester, pl. xxxvi в, fig. 1. "Transverse section of a primary bar. B.v. Blood-vessel connected with the lateral branches of the median endostylarvessel. fiss. Fissure due to the bilateral origin of the rod. cœ.ep. Cœlomic epithelium. $p g$. Pigmented atrial epithelium."

Fig. 11. Copied from Spengel's fig. 12, pl. xvii. "Outer part of a transverse section through a primary bar. b. $m$. Basal membrane. cök. Cœlomic canal of the bar. $s p$. Skeletal rod. $v k$. Chief vessel in the primary bar."

Fig. 12. Copied from Boveri, fig. 6, pl. xxxii. "Transverse section of a primary gill bar, $v i^{1}$. Inner axial vessel. $v e^{1}$. Outer axial vessel. vc. Cœlomic vessel. cœ. Cœlom."

Fig. 13.-A tongue rod in section, to show the skeletal blood-vessel (sk. $b$. v.) running in a special canal; it is probably about to anastomose with the somatic vessel (som. b. v.). Around the cœlom (col.) three nuclei (n.c.ep.) are present, embedded in granulations (? protoplasm). In this section the two blood-vessels, as is frequently the case in cochineal preparations, are stained deep red. The cœlom is quite clear. cu. cutis.

FIG. 14.-A rod from a tongue bar, exhibiting granulations in the cavity, which are of two kinds : a coarser, less deeply stained, in the outer part, which is probably the protoplasm of cœlomic epithelium-in that region marked coe-coelom; and a finer and more deeply staining mass (skel. b. v.), the skeletal blood-vessel. The two are apparently separated by a partition. $n$. is the nucleus of the cœlomic epithelium. som. b. $v$. The outer or somatic blood-vessel. cu. The "cutis" or outer wall of cœlom. From a preparation stained with Mayer's alcoholic cochineal. Drawn under Zeiss's homogeneous immersion.

Fig. 15.-A modification in the shape of the section of the rod, which is not unusual, especially near the synapticula. The rod is here composed of two pieces. The outer wall of the colom is free of skeletal tissue (cf. Fig. 31 ), and the blood-vessel (skel. b. v.) is passing out of the cœlom (cool.), and lies just below the atrial epithelium (at. ep.).

FIg. 16.-Another modification in the tongue bar, which occurs near the upper end of a bar. 
Fig. 17.-Cells from the atrial epithelium of a primary bar, from a partially macerated section (cochineal). $a$. Vacuolated cells. b. More granular, narrower cells, the nucleus being near the free end. c. A portion of a cell, which is probably similar to $d$, with a narrow peripheral portion, and dilated nuclear region below.

FIg. 18.-Three cells of the atrial epithelium of a tongue bar, from a partially macerated section.

Fig. 19.-Cells from the lateral epithelium of a gill bar, from a partially macerated section. The nuclei of the cells are seen to be at different levels. Each cell carries a single long cilium. The small cell to the left may be a portion of a larger cell, or may be really a basal interstitial cell.

Fig. 20.-A small piece of the septal membrane, with a nucleus (n.) (from a transverse section of a bar). The membrane appears to be double, and the nucleus lies between the two sheets.

Fis. 21. - A portion of a longitudinal section of a bar, showing the septal membrane and three elongated, compressed nuclei $(n$.). Only a small portion of the epithelium of the bar is flled in, in order to show the relative size of the nuclei of the septal membrane and those of epithelium (ep.). (Hæmatoxylin. Under Zeiss's apochromatic $4 \mathrm{~mm}$., aperture 95 , with compensating ocular 8.)

Figs. 22-26.-Five consecutive sections to show the passage of a tongue bar into the endostyle, and the communication of the rod cavity with the subendostylar coelom.

Fig. 22. 'Transverse secticn of the endostyle and a neighbouring tongue bar. The details as to arrangement of nuclei are only approximately accurate. It is merely desired to exhibit the general topographical relations of the structures. end. Endostyle. end. sk. Subendostylar skeleton. end. cœl. Subendostylar cœlom. cœ.ep. Nuclei of the colomic epithelium. at. ep. Atrial epithelium. art. Subendostylar artery. $P$. The lowermost part of a primary bar fused with the endostyle. $x$. The peculiar tissue of elongated vacuolated cells (not reticular tissue). T. T. T'ongue bars. rod. 'The contained hollow rod; on the left the bar has already reached and fused with the subendostylar tissue, on the right it is still free.

Fig. 23. The next section. The rod of the tongue bar on the left appears to have a narrow cleft in its wall, so that its cavity communicates wilh the subendostylar cœlom; but this is not so distinct as in the case of the right rod in Fig. 26. ('The lithographer has exaggerated this cleft.)

Fig. 24. The right portion only of the next and following sections is drawn. Here the rod of the tongue bar $(T$.) is distinctly smaller, and approaches the corner of the subendostylar colom. 
Fig. 25. The rod has passed further into the subendostylar tissue, and lies above the corner of the cœlom.

Fig. 26. The cavity of the rod communicates with the subendostylar cœlom most distinctly.

FIGs. 27-29.-Transverse sections of an abnormal primary bar at different levels.

Fig. 27. Section about the middle of the length of the bar. The epithelium and general structure of the bar is normal, but contains three separate primary rods, $1,2,3$, each partially surrounded by a layer of cœlomic epithelium. visc. $v$. The visceral blood-vessel. som.v. The somatic blood-vessel. s.m. The very short septal membrane. cœ. Cœlom. skel. v. Extra-cœlomic skeletal blood-vessel.

Fig. 28. A section of the same bar lower down. There are here only two rods, partially fused; the rod to the right is formed by the fusion of rods 1 and 3 (in Fig. 27).

Fig. 29. The same rod lower down, nearer the endostyle. The two rods have separated again, but have shifted their relative positions.

FIG. 30.-Three sections of a normal primary rod at different levels. (a) Close to the endostyle, where it consists of two independent pieces. (b) Slightly higher up, where a third piece (sometimes isolated) plugs the gap between the two pieces, with which it is more or less fused. (c) The general condition, in which the fusion of the three pieces is complete, except for a narrow axial cleft (? or less refractive substance). $R$. The rod, in the usual sense. $c u$. "Cutis," or outer wall of cœlom. cœ. Cœlom. skel. b. v. Skeletal blood-vessel. som. $v$. Somatic vessel. (Cf. Figs. 13-16.)

FIG. 31 a.-The connection of synapticulum with the primary and tongue bars. The section is accurately transverse, and includes three bars and the synapticulum. $P^{1}, P^{2}$. The two primary bars. $T$. The intervening tongue bar. syn. To the left, half a synapticulum cut along its whole length, and continuous, as is seen, with one half of the tongue rod and the extra-cœlomic "cutis" (cu.) of the primary rod. syn $n^{1} s y n^{2}$. The two portions of the other half of the synapticulum (the intervening portion is in a section not figured). $\quad b . v^{1}$. The subepidermic skeletal blood-vessels of the primary bar. $b . v^{2}$. The skeletal vessel of the tongue bar, which is seen to divide into a right and a left branch, which fall into $b . v^{1}$. of the primary bars. co. Cœlom of the primary bar.

FIG. 31b.-The next section of the primary bar $\left(P^{2}\right)$ showing the passage of $s y n^{2}$. into the cutis $(c u$.). Other letters as in Fig. $31 \alpha$. 


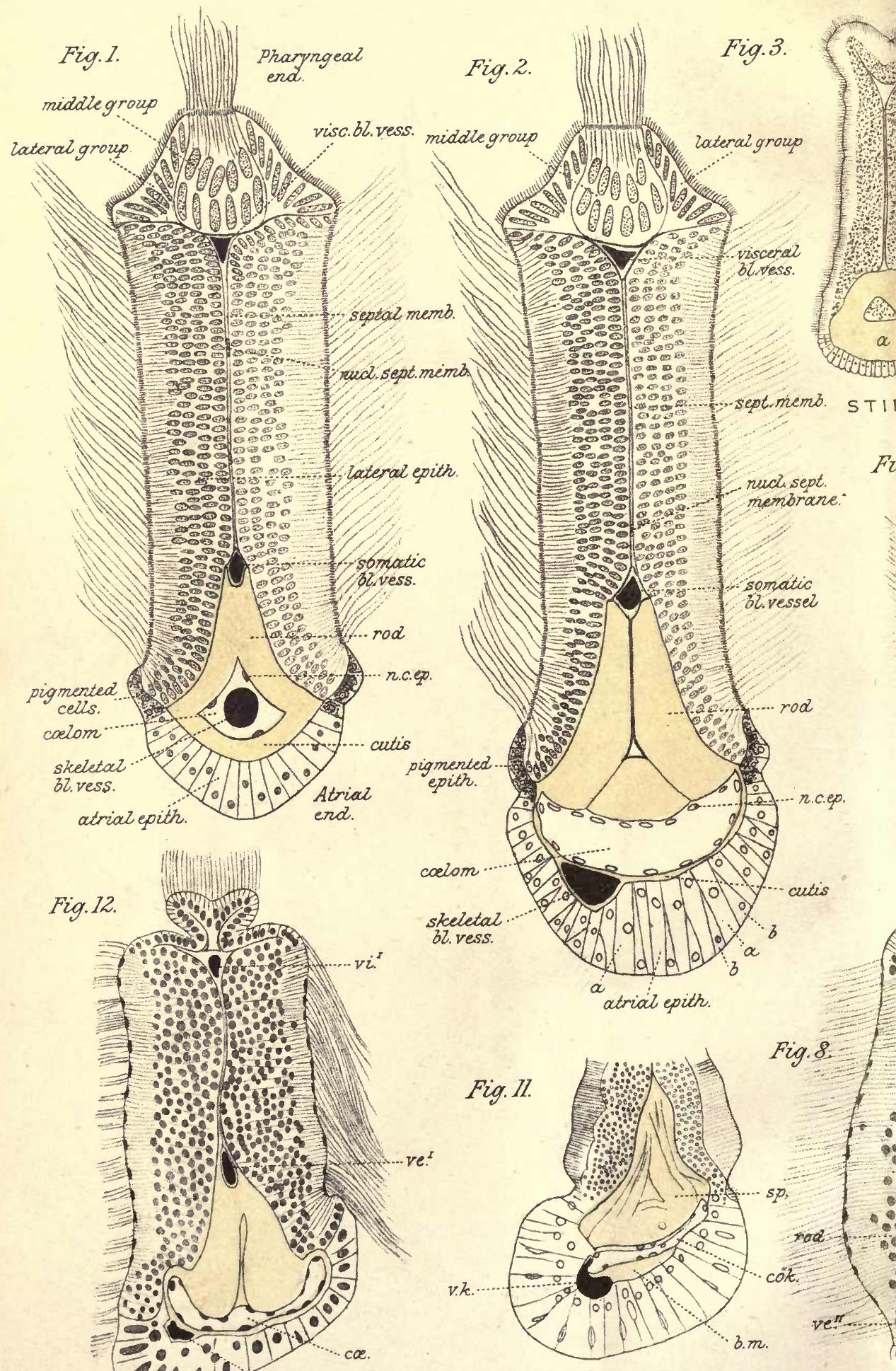

SPENGEL. 


\section{2uart. Zourn. Nicr. Sci. Vot. 35, N.S. Dr. 6.}
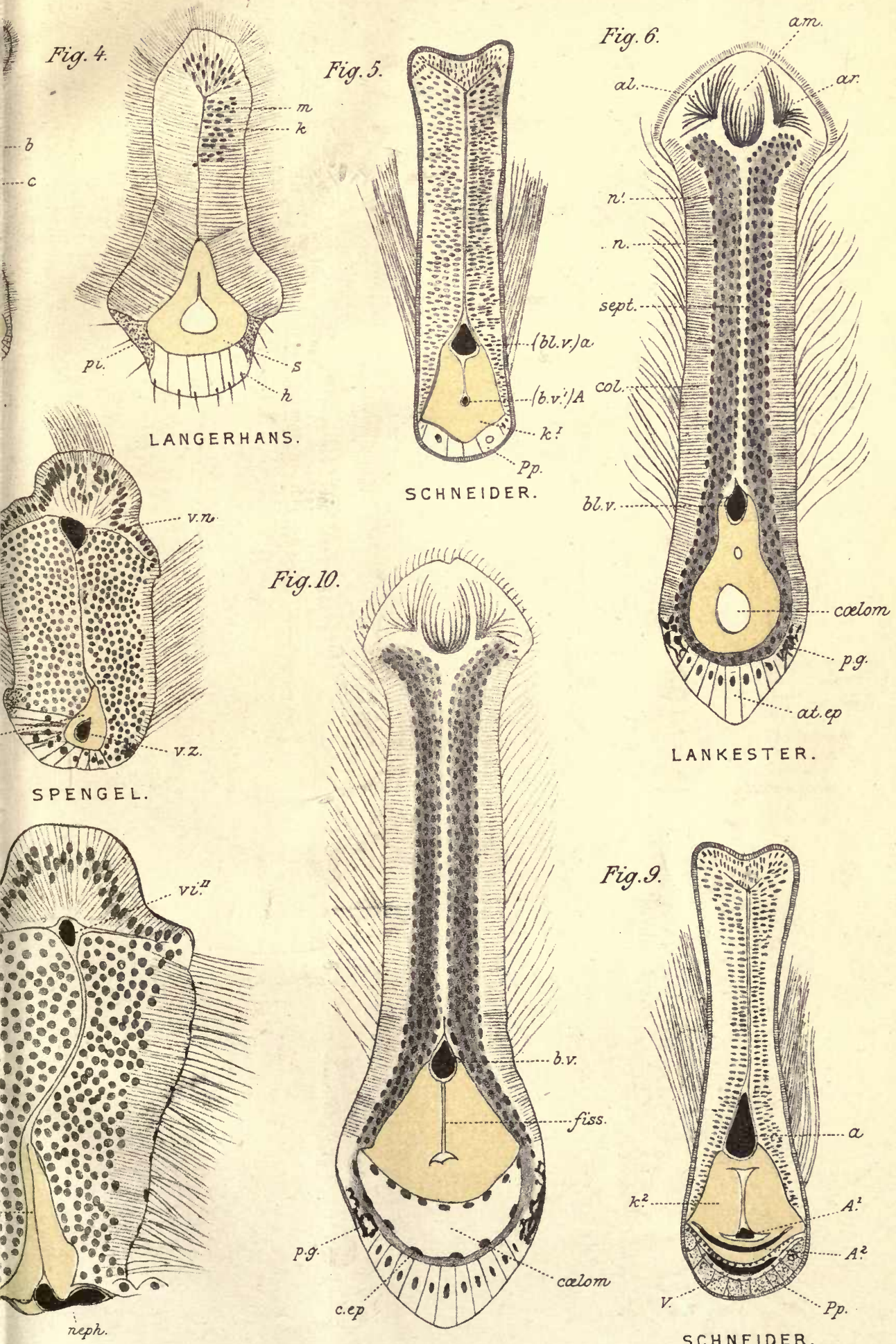

LANKESTER.

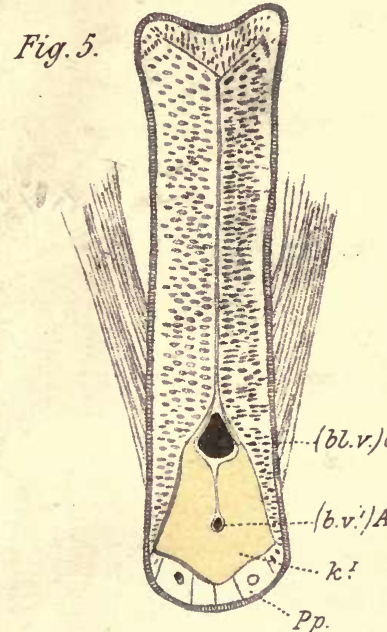

SCHNEIDER.
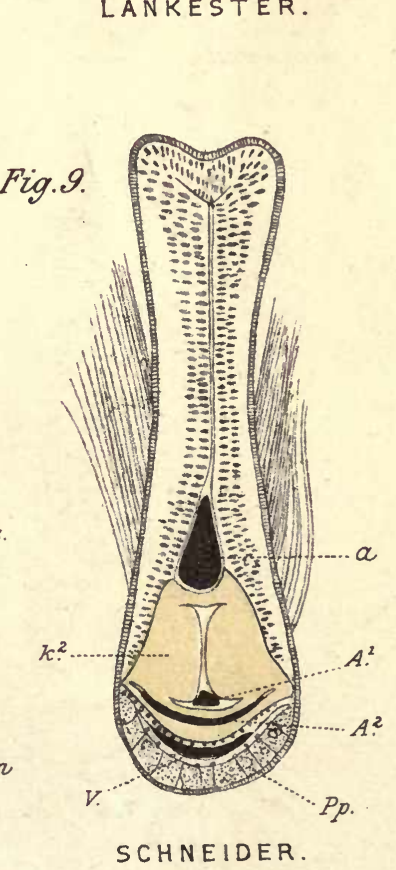


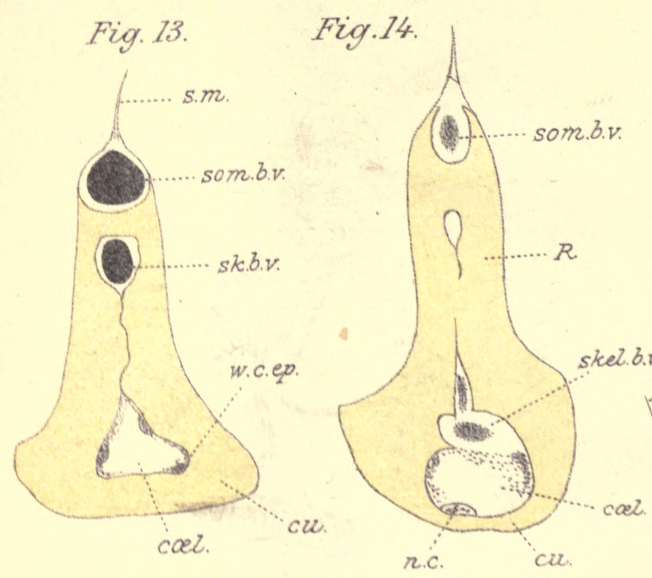

Fig. 15.

cir

Fig. $1 \%$
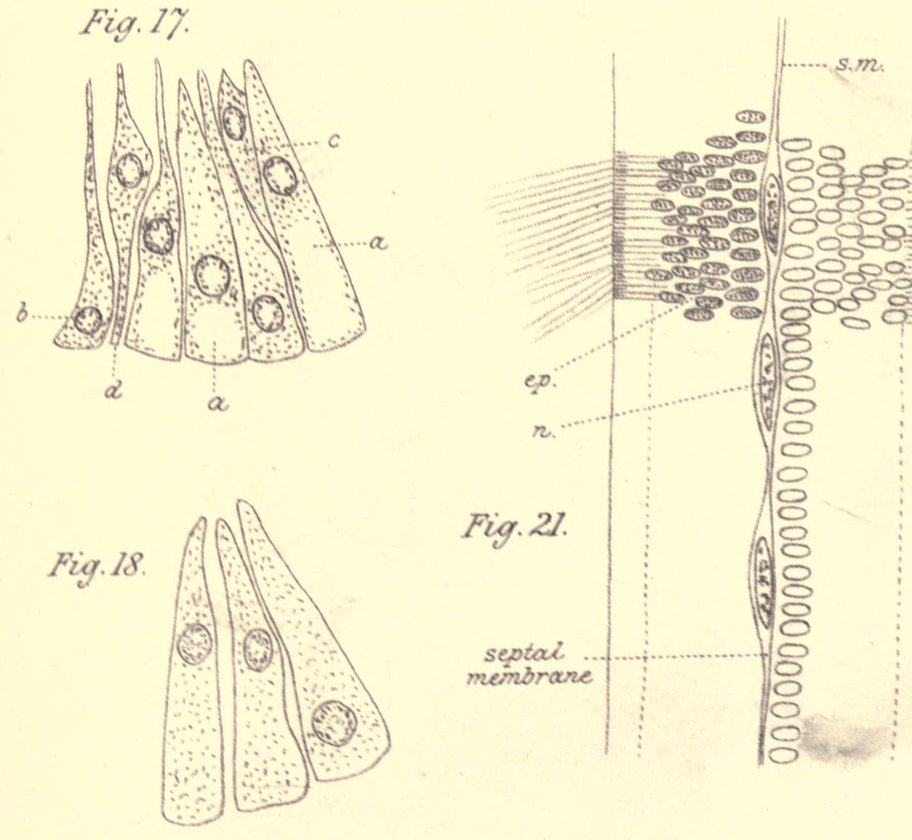

Fig. 30.
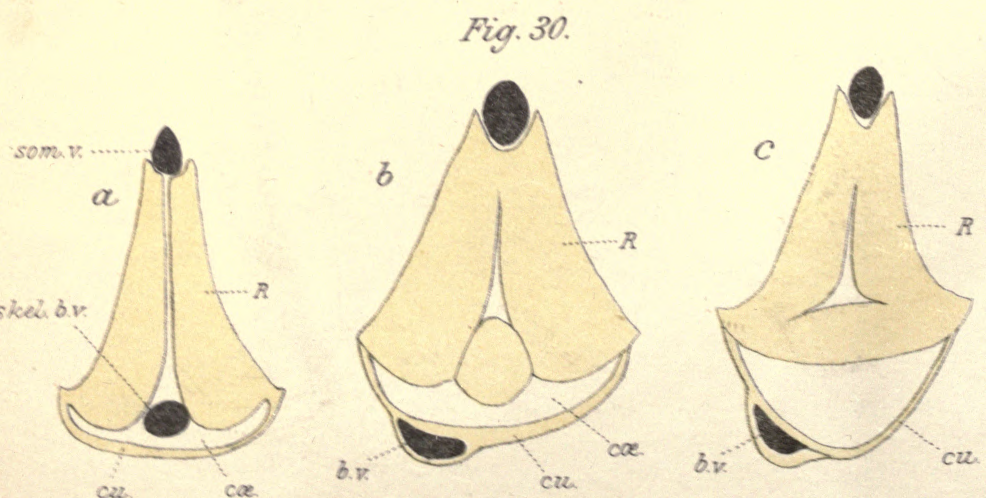

Fig. 19 .

Fig. 20.

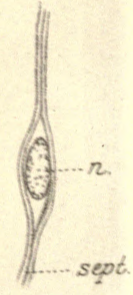

W. B.Benham del. 



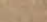
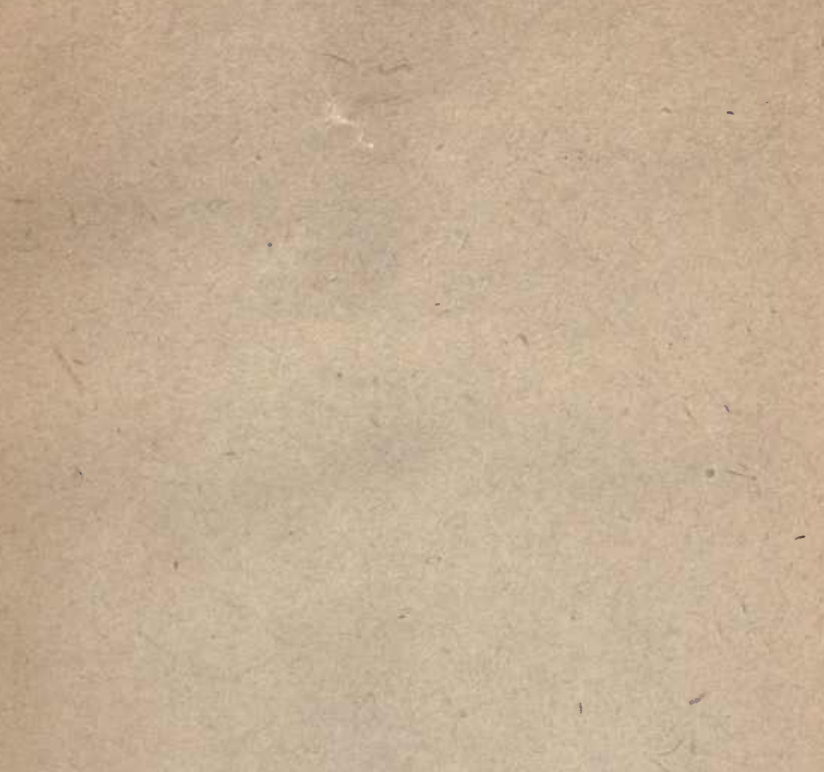


\section{UNIVERSITY OF CALIFORNIA LIBRARY,
BERRELEY}

THIS BOOK IS DUE ON THE LAST DATE

\section{STAMPED BELOW}

$50 \mathrm{c}$ per volume after the thime are subject to a fine of to $\$ 1.00$ per volume after the day overdue, increasin demand may be renewed the sixth day. Books not expiration of loan period.

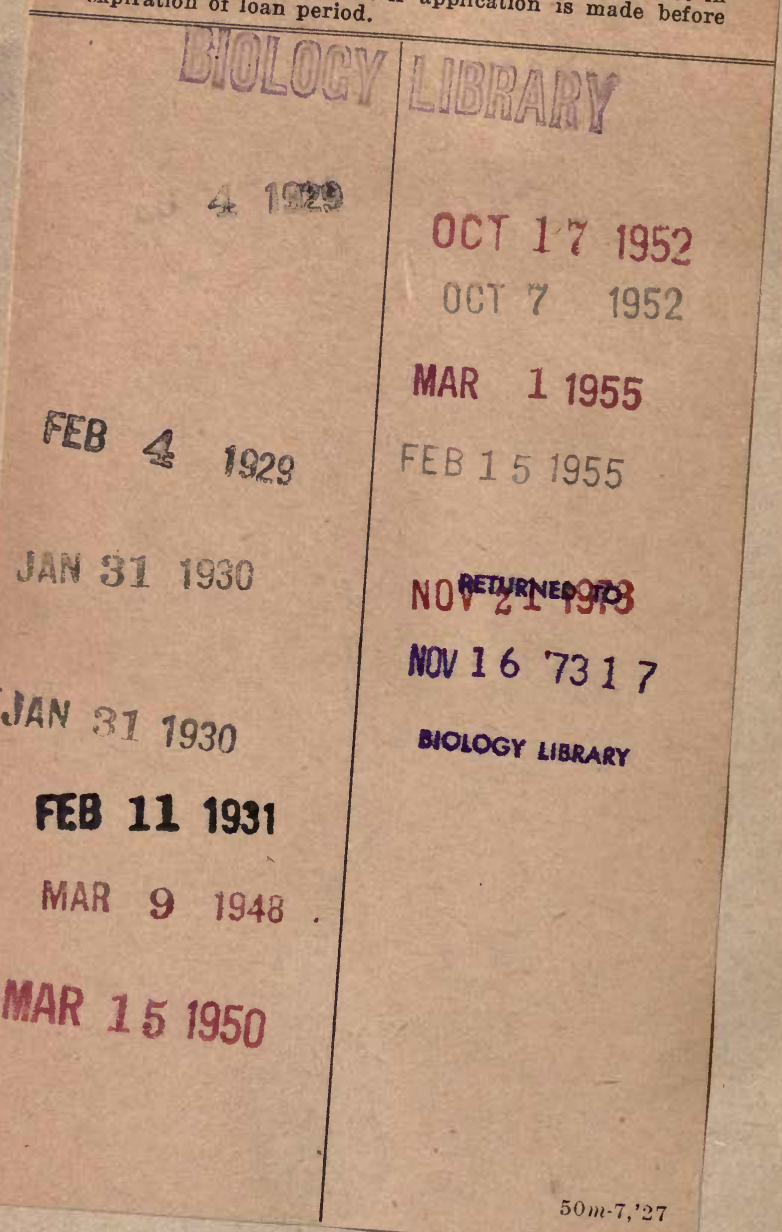




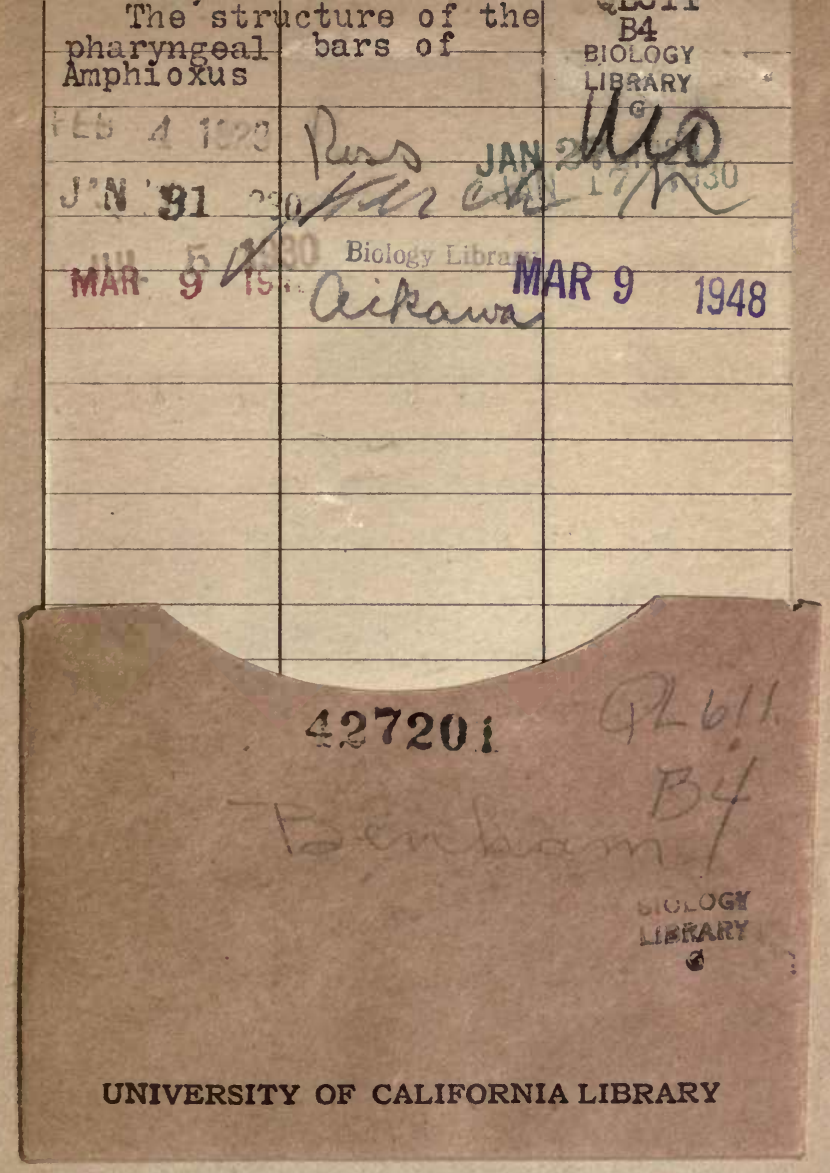


